\title{
Gaps in Utilizing Traveller Health Services in Dubai, Policies, Practises and Protocols
}

Fatima Omer, Nehad Hassan, Hamid Hussain ${ }^{\star}$, Sami Mana and Omer Awad

Department of Preventive Services Centre, Dubai Health Authority, Dubai, UAE

*Corresponding author: Hamid Hussain, Department of Preventive Services Centre, Dubai Health Authority, Dubai, UAE, Tel: 00971502608873; E-mail: hussainh569@gmail.com

Received date: May 06, 2015, Accepted date: July 31, 2015, Published date: August 02, 2015

Copyright: (c) 2015 Omer F, et al. This is an open-access article distributed under the terms of the Creative Commons Attribution License, which permits unrestricted use, distribution and reproduction in any medium, provided the original author and source are credited.

\begin{abstract}
Background: International travel can pose various risks to health, depending on the characteristics of both the traveller and the travel. Travellers may encounter sudden and significant changes in altitude, humidity, microbes, and temperature, which can result in ill health. In addition, serious health risks may arise in areas where accommodation is of poor quality, hygiene and sanitation are inadequate, medical services are not well developed and clean water is unavailable.
\end{abstract}

Objective: To assess knowledge, attitude and practice towards travel health among Dubai's travellers traveling abroad.

Methods: A cross sectional survey was carried out in Jebel Ali Free zone's companies employees where on line self- administrated questionnaire has been distributed to the employees of randomly selected 20 companies. 162 responses were collected.

Results: The study showed that only $22.8 \%$ of respondents had sought pre-travel health advice from travel clinic, $77.8 \%$ of respondents were less than 40 years old, and of $(40.7 \%)$ of respondents planned their trips only one to 2 weeks before travel. The most frequently reported destinations were, Asia $(30.2 \%)$, India $(24.7 \%)$ followed by Africa which constitutes $(16 \%)$. There was a good knowledge regarding importance of vaccination $(96.2 \%)$, and malaria drug prophylaxis $(83.4 \%)$, but there was a low attitude towards vaccinations $(55.6 \%)$.

Conclusions: The result of this short study period provided a valuable insight into the knowledge, attitude and practice of the respondents with significant low awareness of pre-travel health advice as reflected by the low uptake of specialist travel medicine advice with regard to travel vaccinations and malaria Prophylaxis which highlighted an important educational need for Dubai travellers.

Keywords: Gaps; Traveller health; Policies; Dubai

\section{Introduction}

International travel can pose various risks to health, depending on the characteristics of both the traveler and the travel. Travellers may encounter sudden and significant changes in altitude, humidity, microbes, and temperature, which can result in ill health. In addition, serious health risks may arise in areas where accommodation is of poor quality, hygiene and sanitation are inadequate, medical services are not well developed and clean water is unavailable. This can be minimized by suitable precautions taken before, during and after travel [1].

The number of people travelling internationally is increasing every year.Many travellers are putting themselves at risk by failing to take the necessary precautions recommended by the World health organization [1].

Although Dubai is the focus of the fastest-growing tourist and travel industry, few data are available on the knowledge, attitudes and practices (KAP) from this region with regard to determine whether travellers obtain travel health related information about vaccination, malaria chemoprophylaxis, self-treatment, foodborne and waterborne infections, respiratory tract infections, sexually transmitted infections and other infectious diseases and health risk with attention to the itinerary, trip duration, travel style, and health background and activities of the traveler $[1,3]$.

Several surveys have demonstrated that high proportions of travellers are unaware of their travel health risks. In many cases, travelers have not received the immunizations, medications for prophylaxis despite the range of opportunities for travel health advice available [3-5]. A number of reasons explain why this is the case. In part, this is due to low risk perception and lack of awareness of the important of the pre-travel health advice from travelers [6-8]. In other cases, it is a result of the ignorance of health professionals as general practitioners often lack training and knowledge in travel medicine.

Some travellers have clearly received incomplete, sometimes incorrect or misleading advice from Pharmacies, and travel industry and this result in inadequate protection in an important proportion of travelers [9-12].

To ensure that future travellers receive optimal travel health advice and appropriate preventative measures for a safe trip; this study is 
Citation: Fatima O, Nehad H, Hamid H, Sami M, Omer A (2015) Gaps in Utilizing Traveller Health Services in Dubai, Policies, Practises and Protocols. Trop Med Surg 3: 192. doi:10.4172/2329-9088.1000192

Page 2 of 5

carried out to assess knowledge, attitude and practice towards travel health among Dubai's travellers traveling abroad.

\section{Subjects and Methods}

Study setting and design: A cross sectional study was carried out in Jebel Ali free zone located at 40 kilometres, north to Dubai.

Study population: Jebel Ali free zone employees, they are mainly from Europe, Gulf Cooperated Countries, and other Middle East Countries, East Asia including Indian Sub-continent, Far East, Africa, the United States and Caribbean, Australia and New Zealand and United Arab local employees.

There are more than 2200 companies including Jebel Ali Industrial area (according to the Environment and safety office statistics), total number exceed 80,000 employees.

Inclusion criteria:

Large companies in the free zone area

Represents both local and non- local Dubai population

Exclusion criteria:

Companies that their main employees are unskilled labourers

\section{Sampling size and procedure}

Using the computer program Epi-info version "6.04", $12 \%$ estimated soughing traveller health clinic [13], 5\% degree of precision and $95 \%$ confidence interval, the minimum sample size required is $163,10 \%$ of non-response was added, it reached 179 .

Twenty companies' employees, were selected randomly according to the above criteria; only the odd numbers had been selected from between the 40 companies.

\section{Data collection plan}

On line self-administrated questionnaires was distributed through the head office of environment and safety (EHS) email to respondents. They were asked about their knowledge, attitudes towards importance of travel vaccine and malaria prophylaxis in addition to the awareness of the best time for visiting the traveller's clinic and the importance of seeking pre- travel advice.

For those who visited the travel clinic have been asked about the pre travel health advice, and all the respondents were asked about any health problems related to their travel.

\section{Data analysis}

Data was analysed using the software program "SPSS "version 19. Frequency tables with descriptive statistics using mean and standard deviation for quantitative data was carried out. Chi-square test was used for categorical data. $\mathrm{P}<0.05$ was the cut off level of significance.

\section{Results}

\section{Socio-demographic and destinations characteristics}

Table 1 revealed that, the highest percentages of the participants was in the age $30-<40$ years $(43.2 \%)$, followed by the age $<30$ years
(34.6\%) with the mean age of $33.65 \pm 8.71$ years. The majority of them were non-locals and males ( $85.8 \% \& 82.7 \%$ respectively).

\begin{tabular}{|c|c|c|}
\hline Characteristics & No. $(n=162)$ & $\%$ \\
\hline \multicolumn{3}{|l|}{ 1.Socio-demographic } \\
\hline \multicolumn{3}{|l|}{ Age (years) } \\
\hline$<30$ & 56 & 34.6 \\
\hline $30-$ & 70 & 43.2 \\
\hline $40-$ & 27 & 16.7 \\
\hline $50+$ & 9 & 5.6 \\
\hline \multicolumn{3}{|l|}{-} \\
\hline$X \pm S D$ & $33.65 \pm 8.71$ & \\
\hline \multicolumn{3}{|l|}{ Sex } \\
\hline Male & 134 & 82.7 \\
\hline Female & 28 & 17.3 \\
\hline \multicolumn{3}{|l|}{ Nationality } \\
\hline Local & 23 & 14.2 \\
\hline Non-Local & 139 & 85.8 \\
\hline \multicolumn{3}{|l|}{ 2. Destinations } \\
\hline \multicolumn{3}{|l|}{ Destinations } \\
\hline Africa & 26 & 16 \\
\hline India & 40 & 24.7 \\
\hline Asia & 49 & 30.2 \\
\hline Europe & 12 & 7.4 \\
\hline More than one destinations & 35 & 21.7 \\
\hline \multicolumn{3}{|l|}{ 3. Main reasons for travel } \\
\hline Tourism & 91 & 56.2 \\
\hline Business & 35 & 21.6 \\
\hline Tourism \& Business & 17 & 10.5 \\
\hline Others & 19 & 11.7 \\
\hline
\end{tabular}

Table 1: Distribution of the study sample according to sociodemographic and destinations characteristics, Dubai 2013.

The most frequently reported destinations were, Asia, which represents $30.2 \%$ of the travel destinations, India $(24.7 \%)$, followed by Africa (16\%) and travellers to Europe constitute only 7.4\%. The main purpose of the trip was tourism (56.2\%), followed by business (21.6\%). $10.5 \%$ reported both previous reasons for travel.

\section{Knowledge}

Table 2 illustrated that, with regard to the importance of pre- travel advice; it was found that, $64.8 \%$ were able to recognize all the options such as to avoid health problems, taking vaccination, and antimalarial 
Citation: Fatima O, Nehad H, Hamid H, Sami M, Omer A (2015) Gaps in Utilizing Traveller Health Services in Dubai, Policies, Practises and Protocols. Trop Med Surg 3: 192. doi:10.4172/2329-9088.1000192

Page 3 of 5

prophylaxis, $30.2 \%$ of travellers were able to identify only one part of the 4 options for the pre travel consultation which is to avoid health problem abroad.

\begin{tabular}{|c|c|c|}
\hline Variable & No $(n=162)$ & $\%$ \\
\hline \multicolumn{3}{|l|}{ Knowledge } \\
\hline \multicolumn{3}{|l|}{ Importance of pre-travel advice } \\
\hline To avoid health problem & 49 & 30.2 \\
\hline To take vaccination & 6 & 3.7 \\
\hline To take antimalarial & 2 & 1.2 \\
\hline All of the above mentioned advice & 105 & 64.8 \\
\hline \multicolumn{3}{|c|}{$\begin{array}{l}\text { Best time to visit travellers clinic } \\
\text { before travel }\end{array}$} \\
\hline $1-2$ weeks & 66 & 40.7 \\
\hline $2-3$ weeks & 15 & 9.3 \\
\hline $3-4$ weeks & 20 & 12.3 \\
\hline $4-6$ weeks & 41 & 25.3 \\
\hline I don't know & 20 & 12.3 \\
\hline \multicolumn{3}{|l|}{ Importance of vaccination } \\
\hline Yes & 156 & 96.2 \\
\hline No & 3 & 1.9 \\
\hline I don't know & 3 & 1.9 \\
\hline \multicolumn{3}{|l|}{ Importance of antimalarial drug } \\
\hline Yes & 135 & 83.4 \\
\hline No & 8 & 4.9 \\
\hline Do not Know & 19 & 11.7 \\
\hline \multicolumn{3}{|l|}{ Attitude } \\
\hline \multicolumn{3}{|l|}{ Visit to travel clinic if vaccinated } \\
\hline Agree & 52 & 32.1 \\
\hline Not Agree & 90 & 55.6 \\
\hline Do not Know & 20 & 12.3 \\
\hline \multicolumn{3}{|l|}{ Take of antimalarial prophylaxis } \\
\hline Agree & 27 & 16.6 \\
\hline Not Agree & 104 & 64.2 \\
\hline Do not Know & 31 & 19.1 \\
\hline
\end{tabular}

Table 2: Distribution of the study sample according to their knowledge and attitude toward vaccination and antimalarial drug prophylaxis and importance of pre-travel advice, Dubai 2013.

Regarding the best time to visit the traveller's clinic before travel, $40.7 \%$ reported 1 to 2 weeks before travel, whereas $12.3 \%$ stated $3-4$ weeks before travel, and only one quarter $(25.3 \%)$ were aware that the best time is 4 to 6 weeks before travel.
The majority of respondents (96.2\% \& $83.4 \%$ respectively) were aware about the importance of vaccination and antimalarial prophylaxis.

\section{Attitude}

Table 2 demonstrated that, 55.6\% reported disagreement about the towards visiting the traveller's clinic before each travel. On the other hand, $64.2 \%$ recognized the importance of antimalarial drug prophylaxis even if they use the personal prophylactic measures.

\section{Practice}

Concerning visit to traveller's clinic, Table 3 illustrated that, only $22.8 \%$ of travellers sought travel health advice and had visited the travel health clinic before travel. Among those who did not seek pretravel health advice, $44 \%$ were not aware of the need to do so as no body advise them, $42.4 \%$ sought pre-travel advice about their destination from their family doctor, $8.8 \%$ felt that they already knew what to do to protect their health while traveling. 3.2\% of travellers thought that vaccines were expensive.

\begin{tabular}{|l|l|l|}
\hline Variable & No. $(\mathbf{n}=\mathbf{1 6 2})$ & $\%$ \\
\hline Visit the traveller's clinic before travel & & \\
\hline Yes & 37 & 22.8 \\
\hline No & 125 & 77.2 \\
\hline $\begin{array}{l}\text { Reasons for not visiting traveller's } \\
\text { clinic' }\end{array}$ & 55 & \\
\hline No body inform me & 53 & 44 \\
\hline I use to see my family doctor & 11 & 42.4 \\
\hline Because I know what to do & 2 & 8.8 \\
\hline Far away from my place & 4 & 1.6 \\
\hline Expensive & 3.2 \\
\hline
\end{tabular}

Table 3: Distribution of the study sample according to their visits to the traveller's clinic, Dubai 2013.

•Excluding those who visit the traveller's clinic

Table 4 illustrated that the majority of travellers aged $<30$ years $(82.1 \%)$ were more likely to visit the travel clinic before their travel followed by those age $30-<40$ years $(77.1 \%)$ and only $55.6 \%$ of those aged 50 years or more ever visited the clinic. Males and non-locals were more likely to visit the travel clinic than females and non-locals, but all theses the differences were not statistically significant.

Regarding the health advice received in travel health clinic (Table 5), it was found that; $75.7 \%$ of the respondents received health advice about each of the vaccination and food/water, $54.1 \%$ received advice about traveller's diarrhoea and $35.1 \%$ about malaria prophylaxis.

\begin{tabular}{|l|l|l|l|l|l|}
\hline & & $\begin{array}{l}\text { Visited } \\
\text { traveller's } \\
\text { clinic }\end{array}$ & & P value \\
\hline $\begin{array}{l}\text { Socio-demographic } \\
\text { characteristics }\end{array}$ & & & & & \\
\hline & & Yes & No & Total & \\
\hline
\end{tabular}


Page 4 of 5

\begin{tabular}{|c|c|c|c|c|c|}
\hline & & $(n=37)$ & $(n=125)$ & $(n=162)$ & \\
\hline \multicolumn{6}{|c|}{ Age (years) } \\
\hline \multirow[t]{2}{*}{$<30$} & No & 10 & 46 & 56 & \\
\hline & $\%$ & 17.9 & 82.1 & 100 & \\
\hline \multirow[t]{2}{*}{$30-$} & No & 16 & 54 & 70 & \\
\hline & $\%$ & 22.9 & 77.1 & 100 & \\
\hline \multirow[t]{2}{*}{$40-$} & No & 7 & 20 & 27 & \\
\hline & $\%$ & 25.9 & 74.1 & 100 & 0.345 \\
\hline \multirow[t]{2}{*}{$50+$} & No & 4 & 5 & 9 & \\
\hline & $\%$ & 44.4 & 55.6 & 100 & \\
\hline \multicolumn{6}{|l|}{ Sex } \\
\hline \multirow[t]{2}{*}{ Male } & No & 28 & 106 & 134 & \\
\hline & $\%$ & 20.9 & 79.1 & 100 & \\
\hline \multirow[t]{2}{*}{ Female } & No & 9 & 19 & 28 & 0.197 \\
\hline & $\%$ & 32.1 & 67.9 & 100 & \\
\hline \multicolumn{6}{|l|}{ Nationality } \\
\hline \multirow[t]{2}{*}{ Local } & No & 6 & 17 & 23 & \\
\hline & $\%$ & 26.1 & 73.9 & 100 & \\
\hline \multirow[t]{2}{*}{ Non Local } & No & 31 & 108 & 139 & 0.434 \\
\hline & $\%$ & 22.3 & 77.7 & 100 & \\
\hline
\end{tabular}

third of the travellers $(67.6 \%)$ were satisfied. Causes of dissatisfaction were; $33.3 \%$ of travellers stated that only some advice given and $16.7 \%$ received only advice about vaccination and $25 \%$ were not satisfied because of the vaccines were expensive.

\begin{tabular}{|l|l|l|}
\hline Satisfaction about travel health services & $\begin{array}{l}\text { No. }(\mathrm{n} \\
=37)\end{array}$ & $\%$ \\
\hline Respondents' satisfaction & & \\
\hline No & 12 & 32.4 \\
\hline Yes & 25 & 67.6 \\
\hline Causes of dissatisfaction & & \\
\hline Only vaccination advice given & 2 & 16.7 \\
\hline Only some advices given & & \\
\hline No any advice given & 4 & 33.3 \\
\hline Expensive & 3 & 25.0 \\
\hline
\end{tabular}

Table 6: Distribution of the study sample according to the satisfaction about the administrated services in the traveller's clinic, Dubai 2013.

* Excluding 25 respondents who are satisfied.

\section{Discussion}

The importance of qualified pre-travel advice consultation is increasing due to the increasing travel in Dubai. The impact of travel medicine on health cannot be ignored. There has been a focus on infectious diseases in travel medicine. This may seem logical, as travel medicine has generally focused on prêt ravel vaccination and disease prophylaxis, and continuous upgrading of knowledge that travellers receive $[1,7]$.

Regarding knowledge, $83.4 \%$ of respondents have knowledge about important of antimalarial prophylaxis and $64.8 \%$ are able to recognize the components or the content of the health advice that should be delivered. This figure consistent with the Australian travelers to developing countries where $76 \%$ of travellers believed that vaccination provides the essential protection [13].

Regarding attitude, the present study revealed that, only $55.6 \%$ of respondents perceived the importance of vaccination and $64.2 \%$ had a positive attitude towards antimalarial drug prophylaxis. This figure is far lower than the figures reported for European traveler's attitude where $80 \%$ considered vaccinations essential, but the figure is consistent with attitude against malaria where $64 \%$ of the European travellers had a positive attitude [14].

In spite of the fact that the random sample was taken from only Jebel Ali Free zone clients in which there were high proportion of experienced business travelers, but the traveller KAP reflect serious shortcomings with regard to vaccines and taking antimalarial prophylaxis, especially in case of travelers practices as only $22.8 \%$ of travellers sought travel health advice from travel clinic before travel which also lower than the Australian, American and European studies where $32 \%, 36 \%$ and $40 \%$ respectively of travellers sought travel health advice from travel health clinic [13-15]. But it is far lower than the Spanish and South African studies where 83.1\% \& 86\% of the traveller respectively sought health-related advice $[16,17]$. On the other hand, it 
is little more higher than the Qatar airport study (19\%) of travellers sought travel health advice [18].

The survey's findings promote the discipline of travel medicine as a separate specialty. It is clear that Dubai travelers are better satisfied with advice received from travel medicine specialists $(67.6 \%)$.

Of particular concern is that only $22.8 \%$ of travellers sought travel health advice from travel clinic before departure. The reason for this low percentage may be a result of low risk perception as $44 \%$ of the respondents stated that they did not seek prêt ravel advice because nobody advise them to do so. Another important factor also is the increasing number of last minute travellers that suggest that time and convenience are substantial factors as $40.7 \%$ of the respondents planned their trip less than 2 weeks before travel. These reflect that the last-minute travellers were a key group to consider for targeted travel health advice and support from health professionals and other institutions is highly needed, particularly family physicians, are important in the field of travel medicine, and further training in the field of travel medicine is advised as $42.4 \%$ of respondents stated that they use to see their family doctor before.

Many travelers suggested increasing the awareness about travel clinic through travel agency, when they purchase their tickets, at the same time, the travel agency can direct them to the travel health clinic and the travel health web site, which they can consult. However, two recent studies suggested travel agents are interested in the issue of travel health and see themselves play a role in referring clients to travel clinics and/or distributing health information prepared by travel clinic [19], which might be interesting, provided high-quality information or referral is made available $[19,20]$.

\section{Conclusion and Recommendations}

In summary, there is a considerable shortcoming in KAP with significant low awareness of pre-travel health advice as reflected by the low uptake of specialist travel medicine advice $(22.8 \%)$, with regard to travel vaccinations and malaria Prophylaxis with documented preventable diseases such as respiratory diseases, traveller's diarrhoea, typhoid and injuries. Therefore there is an urgent need to increase awareness of the travel medicine for Dubai traveler's through media attention, simple health education material and travel web sites for both public and health professionals.

Training of general practitioners, medical students, postgraduate, pharmacist and other related health institutions. Travel agencies could be provided with educational material developed by travel medicine clinic and can also play a role in referring traveller's to travel clinics, would be the best strategies to improve this situation.

Standardized airport questionnaire surveys should be carried out at regular intervals to monitor the success of such interventions.

\section{References}

1. World Health Organization. International Travel and Health. Geneva: World Health Organization; 2012 [cited 2013 Jan. 25]. Available from: http://www.who.int/ith/en/.

2. United Nations World Tourism Organization. UNWTO World Tourism Barometer, Vol. 10 (September). Madrid: United Nations World Tourism Organization; 2012 [cited 2012 Dec. 15]. Available from: http:// dtxtq4w60xqpw.cloudfront.net/sites/all/files/pdf/ unwto_barom12_05_sept_excerpt.pdf.
3. Hatz CFR, Chen LH (2013) Pre-travel consultation. In: Keystone JS, Freedman DO, Kozarsky PE, Connor BA, Nothdurft HD, editors. Travel Medicine. 3rd ed. Philadelphia: Saunders Elsevier; p 31-6.

4. Freedman DO, Weld LH, Kozarsky PE, Fisk T, Robins R, et al. (2006) Spectrum of disease and relation to place of exposure among ill returned travelers. N Engl J Med 354: 119-130.

5. Chen LH, Hill DR. PIER Module: Travel immunizations. Philadelphia, PA: American College of Physicians [cited 2012 Sep 18]. Available from: http://pier.acponline.org/physicians/procedures/physpro272/ physpro272-wn.html

6. Angell SY, Behrens RH (2005) Risk assessment and disease prevention in travelers visiting friends and relatives. Infect Dis Clin North Am 19: 49-65.

7. International Society of Travel Medicine. The body of knowledge for the practice of travel medicine. Atlanta: International Society of Travel Medicine; 2006 [cited 2012 Sep 18]. Available from: https:// www.istm.org/WebForms/Members/MemberResources/Cert_Travhlth/ Body.aspx

8. Steffen R, Amitirigala I, Mutsch M (2008) Health risks among travelers-need for regular updates. J Travel Med 15: 145-146.

9. Piotte E, Bellanger AP, Piton G, Millon L, Marguet P (2013) Pre-travel consultation: evaluation of primary care physician practice in the Franche-Comté region. J Travel Med 20: 221-227.

10. Hatz CFR, Chen LH. Pre-travel consultation. In: Keystone JS, Freedman DO, Kozarsky PE, Connor BA, Nothdurft HD, editors. Travel Medicine. 3rd ed. Philadelphia: Saunders Elsevier; 2013: p. 31-6.

11. Chen LH, Wilson ME, Davis X, Loutan L, Schwartz E, et al. (2009) Illness in long-term travelers visiting GeoSentinel clinics. Emerg Infect Dis 15: 1773-1782.

12. Toovey S (2006) Malaria chemoprophylaxis advice: survey of South African community pharmacists' knowledge and practices. J Travel Med 13: $161-165$.

13. Wilder-Smith A, Khairullah NS, Song JH, Chen CY, Torresi J (2004) Travel health knowledge, attitudes and practices among Australasian travelers. J Travel Med 11: 9-15.

14. Van Herck K, Van Damme P, Castelli F, Zuckerman J, Nothdurft H, et al. (2004) Knowledge, attitudes and practices in travel-related infectious diseases: the European airport survey. J Travel Med 11: 3-8.

15. Hamer DH, Connor BA (2004) Travel health knowledge, attitudes and practices among United States travelers. J Travel Med 11: 23-26.

16. Lopez-Velez R, Bayas JM (2007) Spanish travelers to high-risk areas in the tropics: airport survey of travel health knowledge, attitudes, and practices in vaccination and malaria prevention. J Travel Med 14: 297-305.

17. Toovey S, Jamieson A, Holloway M (2004) Travelers' knowledge, attitudes and practices on the prevention of infectious diseases: results from a study at Johannesburg International Airport. J Travel Med 11: 16-22.

18. Al-Hajri MM (2008) Traveller's preventive health measures against infectious diseases and physicians' awareness toward travel medicine in Qatar 2007. Unpublished thesis of Arab Board in Community Medicine. Knowledge, Attitudes and Practice of Travellers regarding Prevention of Infectious Diseases and Primary Care Physicians Practice and Awareness Toward Travel Medicine in Qatar, Qatar International Airport, departure lounge, June - July 2007.

19. Provost S, Gaulin C, Piquet-Gauthier B, Emmanuelli J, Venne S, et al. (2002) Travel agents and the prevention of health problems among travelers in Québec. J Travel Med 9: 3-9.

20. Lawlor DA, Burke J, Bouskill E, Conn G, Edwards P, et al. (2000) Do British travel agents provide adequate health advice for travellers? $\mathrm{Br} \mathrm{J}$ Gen Pract 50: 567-568. 